\title{
Anastomosis of the ovarian vein to the hepatic portal vein in sheep induces ovarian hyperstimulation associated with increased LH pulsatility, but only in the absence of the contralateral ovary
}

\author{
D Garcès ${ }^{1}$, J C Mariana ${ }^{2}$, M R Blanc ${ }^{2}$, P G Knight ${ }^{3}$, \\ D Monniaux ${ }^{2}$, A Collet ${ }^{2}$, C Pisselet ${ }^{2}$, J Fontaine ${ }^{2}$ and J C Poirier ${ }^{2}$ \\ ${ }^{1}$ Clinique St Côme et St Damien, 41000 Blois, France \\ ${ }^{2}$ INRA, Station de Physiologie de la Reproduction des Mammifères Domestiques, 37380 Nouzilly, France \\ ${ }^{3}$ School of Animal and Microbial Sciences, The University of Reading, Whiteknights, Reading RG6 6AJ, UK \\ (Requests for offprints should be addressed to J C Mariana)
}

\begin{abstract}
In this study, two experiments were performed, the first of which examined the ovarian response in ewes that were subject to unilateral ovariectomy (ULO) at different intervals (0-14 days) after surgical anastomosis (AN) of the ovarian vein to the mesenteric vein $(n=7$ ewes), or sham operation (SO; $n=4$ ewes). Hypertrophy and development of multiple follicular and luteal structures on AN ovaries were observed after ULO, while SO ovaries remained of normal size and appearance after ULO. The second experiment involving 11 ewes (five AN; six SO) aimed to clarify the mechanism by which AN following ULO-induced ovarian hypertrophy and increased follicle development. The results confirmed that there were more large $(>5 \mathrm{~mm}$ ) follicles on AN compared with SO ovaries; however, their rate of atresia was similar. Oestradiol and progesterone concentrations in follicular fluid of class 1 follicles $(5-9 \mathrm{~mm})$ were higher in AN ovaries than those in control follicles of the same size collected in the late follicular phase of an induced oestrous cycle. In AN ewes, intrafollicular progesterone concentrations increased while follicular aromatase activity and intrafollicular oestradiol, inhibin A, follistatin and activin A concentrations all decreased as follicle size increased. Oestradiol and proges-
\end{abstract}

terone concentrations were substantially higher in ovarian venous blood than in hepatic venous blood, both in AN and SO ewes, whereas inhibin A levels were not significantly modified by passage through the liver in either group. Mean plasma LH concentration, and LH pulse frequency and amplitude increased markedly after AN but were not affected by SO. Plasma FSH showed only a small transient increase after AN, presumably due to the maintenance of inhibin feedback. Injection of prostaglandin $F_{2 \alpha}$ 4 days later did not further modify LH or FSH secretion in either group. Full ovariectomy (FO) 9-14 days after AN or $\mathrm{SO}$ increased $\mathrm{LH}$ secretion markedly in $\mathrm{SO}$ ewes but to a lesser degree in AN ewes; FO induced a large and rapid increase in FSH levels in both groups. In conclusion, AN of the ovary to the liver via the mesenteric vein provides a useful model for studying the feedback between the ovary and the hypothalamo-pituitary system and the mechanisms controlling follicle development. The present results indicate that the pattern of LH secretion is an important factor controlling the terminal phase of follicle development in the ewe.

Journal of Endocrinology (2000) 165, 411-423

\section{Introduction}

The mechanisms that control the terminal phase of follicular growth and ultimately determine ovulation rate are poorly understood but are considered to involve interactions between both endocrine signals and intraovarian autocrine/paracrine regulatory systems. In the ewe, as in several species, the roles of gonadotrophins have been extensively studied. Follicle-stimulating hormone (FSH) is critical for follicle selection and once selected luteinizing hormone (LH) alone is sufficient to drive the selected follicles to ovulation. For example, Campbell et al.
(1995) showed that in sheep exogenous LH alone is sufficient to drive one follicle to ovulate, if during a preliminary period the ovary is stimulated by $\mathrm{FSH}$ and $\mathrm{LH}$ in a pulsatile mode. Similarly, McNeilly et al. (1992) showed that an appropriate balance between FSH and LH is necessary in sheep to select preovulatory follicles. It was concluded that each ewe has its own threshold for FSH in relation to the growth of the largest preovulatory follicles and that the effect of $\mathrm{LH}$ pulses depends on their amplitude and on prevailing plasma FSH concentration. Actually the hormonal treatments used to stimulate the ovaries, even if they are devised to closely mimic normal 
conditions, are always imposed on ovaries. Consequently the ovaries do not participate in the feedback mechanism which normally provides their own stimulation, as under normal physiological situations. Thus, it is conceivable that threshold phenomena can be generated artificially in response to administration of exogenous hormones (Mariana 1970, Brown 1978, Picton \& McNeilly 1991).

Evidence suggests that the feedback action of the ovary on the hypothalamo-pituitary complex is a key factor in the regulation of terminal follicular growth and ovulation rate (Mann et al. 1992, McNeilly et al. 1992, Scaramuzzi et al. 1993, Knight 1996). Experiments involving passive or active immunization against inhibin, oestradiol, androstenedione or testosterone have provided valuable insights into the complexity of this feedback system (Martensz \& Scaramuzzi 1979, Martensz et al. 1979, Campbell \& Scaramuzzi 1995, Terqui et al. 1995). For instance, passive immunization of ewes against inhibin during the luteal phase of the oestrous cycle raises plasma concentration of FSH without modifying LH concentration (Mann et al. 1989) and increases ovulation rate (Wheaton et al. 1996). In contrast, Campbell et al. (1991) observed in androstenedione-immunized ewes an increase in ovulation rate that was associated with higher plasma LH but no change in plasma FSH level. While immunization against steroids and inhibin is generally considered to modify ovarian function by perturbing feedback systems between the ovary and the hypothalamo-pituitary system, these procedures may also have direct actions at the intraovarian level, as indicated recently by Tannetta et al. (1998).

We recently developed an experimental model in the ewe in which most of the steroids secreted by one ovary are prevented from reaching the peripheral circulation (Garcès \& Mariana 1997). The model involves anastomosing the ovarian vein to the portal hepatic vein through the mesenteric vein. After anastomosis (AN), the steroids normally secreted by that ovary are catabolized by the liver. In the absence of the contralateral ovary, steroid levels in peripheral blood are close to those measured in a castrated animal (Garcès \& Mariana 1997). A considerable advantage of the model is the ability to selectively prevent steroids secreted by the single AN ovary from reaching the hypothalamo-pituitary system, whilst the other ovary continues to function normally. It is suggested that the model produces (i) a functional hemicastrate when the contralateral ovary remains in situ, and (ii) a functional castrate when the contralateral ovary is removed.

In this study, we have examined in further detail the effect of ovarian steroid suppression using the surgical AN model (i) to analyse more thoroughly the endocrine modifications induced by AN, particularly with regard to FSH and LH secretion, and (ii) to clarify the mechanisms through which so many large follicles appear after the AN procedure.

\section{Materials and Methods}

Two experiments were carried out, the first being a preliminary study to establish the effects of AN on ovarian follicular populations in ewes in which the contralateral ovary was still present at the time of AN but was removed subsequently. In the second experiment, involving unilaterally ovariectomized (ULO) ewes, more detailed analysis of FSH and LH levels in peripheral blood as well as biochemical analysis of large follicles following AN or sham operation ( $\mathrm{SO}$ ) were undertaken. In addition, samples of ovarian vein blood and hepatic vein blood were collected for analysis of ovarian steroids and peptides.

\section{Experimental design}

Preliminary experiment Eleven ewes were used, four of the Romanov breed (one SO, three $\mathrm{AN}$ ) and seven of the Ile-de-France breed (three SO, four AN). Sheep were previously checked for cyclicity. They were synchronized by means of a vaginal sponge coated with $40 \mathrm{mg}$ fluorogestone acetate (FGA; Intervet, Angers, France) retained for 12 days. Between 10 and 12 days after the progestagen sponge removal, the right ovary was either anastomosed (AN group) or sham operated (SO group). In the latter group, the left ovary was simultaneously removed. One or 2 days before or after surgery, all ewes (AN and $\mathrm{SO}$ groups) received $2.5 \mathrm{mg}$ prostaglandin $\mathrm{F}_{2 \alpha}\left(\mathrm{PGF}_{2 \alpha}\right)$ i.m. (Estrumate; Ceutravet Plaucoet, France) to induce luteolysis (Garcès \& Mariana 1997). In the AN group the left ovary was removed between 0 and 14 days after AN surgery and corpora lutea $(\mathrm{CL})$ present on both ovaries were counted at this time. The right ovary was subsequently removed 12-42 days after AN or 5-9 days after SO.

Experiment 2 Eleven ewes of the Ile-de-France breed were subjected to ULO (left ovary removed) 2 months before the experiment. Ewes were synchronized as in experiment 1; 10 days after removal of the FGA sponge they were subjected to either AN $(n=5)$ or SO $(n=6)$. Four days later each ewe received $2.5 \mathrm{mg} \mathrm{PGF}_{2 \alpha}$ i.m. Ewes were subsequently ovariectomized either 9 days (three SO, three AN) or 13 days (three SO, two AN) after AN/SO surgery. Two SO ovaries and two AN ovaries were fixed for classical histology and three SO and three AN were collected for biochemical characterization of follicles. Jugular vein blood samples were collected daily at $0900 \mathrm{~h}$ throughout the study for measurement of plasma FSH. On the day of surgery, the blood sample was taken before anaesthesia and surgery. As illustrated in Fig. 1, additional samples were collected at 15 min intervals for $8 \mathrm{~h}$ on four separate days to assess pulsatile $\mathrm{LH}$ secretion. A single blood sample was collected from each hepatic and ovarian vein at the time of right ovary removal according to the procedure described by Garcès \& Mariana (1997) for measurement of inhibin, oestradiol and progesterone 


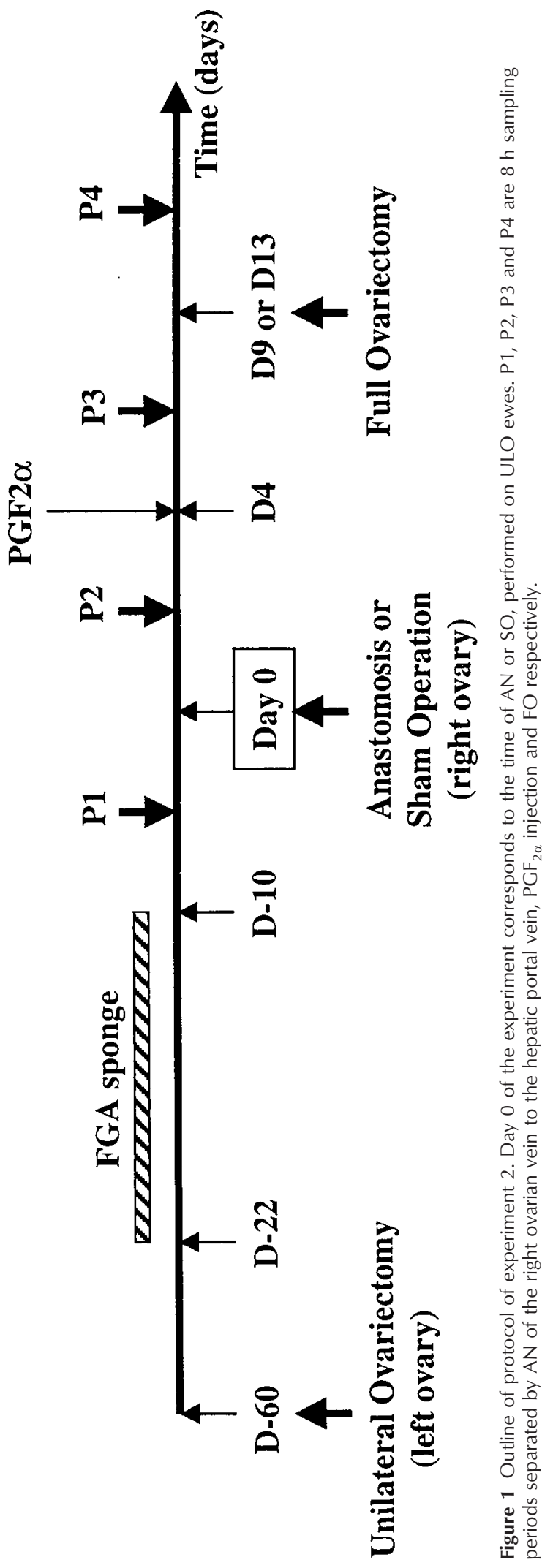


levels. To assess the effect of the AN on the peripheral steroid levels, blood was collected 3 days after S0 or AN to measure progesterone levels and 2 days after $\mathrm{PGF}_{2 \alpha}$ to measure oestradiol levels.

\section{Surgical techniques}

Sheep were handled according to the guidelines on the handling and training of laboratory animals (University Federation for Animal Welfare). The procedure used to anastomose the ovarian vein to the mesenteric vein is described in detail elsewhere (Garcès \& Mariana 1997). The success of the procedure was assessed by measuring peripheral levels of progesterone from 5 to 9 days after surgery (Garcès \& Mariana 1997). Two sheep which did not exhibit the expected sharp decrease in progesterone levels after AN surgery were eliminated from the experiment. The AN procedure did not induce any visible secondary effects on the animals, which remained in perfect health throughout the study.

\section{Ovarian analysis}

The ovaries collected by surgery were immediately dipped in Bouin-Hollande fixative except for one that was dramatically enlarged (between 50 and $60 \mathrm{~mm}$ ) and could not be processed for histology. After fixation, ovaries were embedded in paraffin wax and serially sectioned at a thickness of $7 \mu \mathrm{m}$; every fifth section was mounted and stained with Mayer's hemalun solution and observed. Antral follicles were counted, measured and classified as atretic or non-atretic. A follicle was classified as atretic when five or more pyknotic bodies were observed bordering or within the granulosa cells of the section studied. All measurements were made on the section where the oocyte was found, except for the largest follicles, for which measurements were recorded from the largest section limited by the basement membrane. The diameter of each follicle was determined using a semi-automatic image analyser (Leitz, France).

The number of CL on each ovary was recorded at the time of ULO or full ovariectomy (FO). We confirmed by histology that luteal structures were either luteinized unruptured follicles or CL.

\section{Biochemical characterization of follicles (steroidogenesis and peptides of the inhibin system)}

Recovery of follicular fluids and granulosa cells Biochemical characterization of large ovarian follicles was performed on three AN ewes of experiment 2, by comparison with follicles from three control ewes. AN ovaries were recovered surgically 9 days after AN. Control ovaries were recovered at slaughter in the late follicular phase of an induced oestrous cycle ( $36 \mathrm{~h}$ after removal of an intravaginal $40 \mathrm{mg}$ FGA sponge). Individual large follicles (diameter $>4.5 \mathrm{~mm}$ ) were dissected and measured with a millimetre scale. Follicular fluids were recovered and stored individually at $-20{ }^{\circ} \mathrm{C}$ until assayed for steroids (oestradiol-17 $\beta$, progesterone, androstenedione) and peptides of the inhibin system (inhibin A, activin A, follistatin). After antral fluid was removed, the collapsed follicle was slit open in $250 \mu$ l heparinized medium B2 (Ménézo 1976) and a suspension of granulosa cells was prepared as previously described (Monniaux 1987). For each suspension, a smear of granulosa cells on a histological slide was prepared with a sample of $10 \mu \mathrm{l}$ cell suspension, fixed in methanol-formaldehyde-acetic acid (80:15:5, v/v), and subsequently stained with Feulgen stain. The quality of each follicle was assessed a posteriori by microscopic examination of smears, using classic histological criteria; follicles were judged healthy when no pyknotic bodies were present in granulosa cells. The remaining cell suspension was used to determine aromatase activity, as described below.

Determination of aromatase activity of granulosa cells The method previously described (Monniaux 1987) was used. Briefly, $50 \mu \mathrm{l}$ granulosa cell suspension were incubated (in duplicate) for $1 \mathrm{~h}$ at $37{ }^{\circ} \mathrm{C}$ in the presence and absence of testosterone $\left(10^{-7} \mathrm{M}\right)$ as a substrate for aromatase (final volume of incubation $500 \mu \mathrm{l}$ ). Incubations were terminated by centrifugation $(300 \mathrm{~g}, 7 \mathrm{~min})$ and individual supernatants were stored at $-20{ }^{\circ} \mathrm{C}$ until assayed for oestradiol-17 $\beta$. Aromatase activity was calculated by substracting basal oestradiol levels (measured in the absence of testosterone in the incubation medium) from levels obtained in the presence of testosterone as a substrate in incubations, and expressed as the amount of oestradiol-17 $\beta$ secreted by $10^{5}$ viable cells per hour.

\section{Hormone assays}

RIA of steroids in incubation medium and follicular fluid For supernatants of cell incubations, a direct assay of oestradiol-17 $\beta$ was performed. For follicular fluids, after extraction of $10 \mu \mathrm{l}$ fluid with $10 \mathrm{ml}$ ethyl acetatecyclohexane $(1: 1, \mathrm{v} / \mathrm{v})$, the dried extracts containing steroids were recovered in PBS then assayed by RIA for oestradiol-17 $\beta$, progesterone and androstenedione. Oestradiol-17 $\beta$ was assayed using the technique of Thibier \& Saumande (1975). The minimal detectable level was $1.5 \mathrm{pg} /$ tube. The intra- and inter-assay coefficients of variation $(\mathrm{CVs})$ were 9 and $10 \%$ respectively. Progesterone was assayed using the method of Saumande et al. (1985). The minimal detectable level was $12 \mathrm{pg} /$ tube. The intraand inter-assay CVs were 10 and $11 \%$ respectively. Androstenedione was assayed using the method of Bosc \& Nicolle (1997). The minimal detectable level was $2.5 \mathrm{pg} /$ tube and the intra-assay CV was $11 \cdot 6 \%$. All samples were analysed in the same assay.

Plasma hormone assays Plasma $\mathrm{LH}$ and FSH levels were determined by specific RIA (Pelletier et al. 1968, 
Blanc \& Poirier 1979) and the results were respectively expressed as ng LH CY 1051 (preparation equivalent to 2.5 times US National Institutes of Health (NIH) standard LH NIH S1) and FSH HG 225 (preparation equivalent to $4 \cdot 3$ times NIH FSH S3) per ml plasma. The minimal detectable level was $0.4 \mathrm{ng} / \mathrm{ml}$ for LH and $1.1 \mathrm{ng} / \mathrm{ml}$ for FSH, measured at a bound with unlabelled/bound without unlabelled hormone ratio (B/B0) of 95\%. LH intraand inter-assay $\mathrm{CVs}$ at $\mathrm{B} / \mathrm{B} 0=50 \%$ were $7 \cdot 3$ and $11 \cdot 2 \%$ respectively. $\mathrm{FSH}$ intra-assay $\mathrm{CV}$ at $\mathrm{B} / \mathrm{B} 0=50 \%$ was $9 \cdot 2 \%$. All samples were measured in one assay for FSH. As plasma FSH levels were previously shown to be nonpulsatile (Blanc \& Poirier 1979) blood samples were collected once a day.

Oestradiol-17 $\beta$ and progesterone were measured using a previously described RIA (Saumande 1981, Saumande et al. 1985). Oestradiol-17 $\beta$ in ovarian vein plasma was assayed by a direct method using $0.05 \mathrm{ml}$ plasma and desteroidized plasma; the minimum detectable level was $2 \mathrm{pg} / \mu \mathrm{l}$ and the intra- and inter-assay CVs were $10 \%$. The oestradiol-17 $\beta$ assay for hepatic vein plasma was performed using $5 \mathrm{ml}$ plasma extracted with $25 \mathrm{ml}$ cold dichloromethane $\left(-20{ }^{\circ} \mathrm{C}\right)$. Extraction recovery was $80 \cdot 4 \pm 1 \cdot 2 \%$ and the minimal detectable level was $2 \mathrm{pg} / \mathrm{ml}$. Inter- and intra-assay CVs were both $10 \%$. The progesterone assay was performed using $0 \cdot 2 \mathrm{ml}$ hepatic plasma extracted with $2.5 \mathrm{ml}$ hexane. The recovery rate of extraction was $75 \cdot 7 \pm 3 \cdot 8 \%$ and the minimal detectable level was $0 \cdot 1 \mathrm{ng} /$ $\mathrm{ml}$. The intra- and inter-asssay CVs were 12.0 and $17 \cdot 5 \%$ for a reference plasma with a concentration of progesterone of $7 \cdot 1 \mathrm{ng} / \mathrm{ml}$.

\section{Assays of peptides of the inhibin system in follicular fluid and plasma Concentrations of inhibin A in blood plasma and follicular fluid were measured using the two-site ELISA described by Knight et al. (1998). Within- and between-plate CVs were 8 and $11 \%$ respectively and the detection limit was $50 \mathrm{pg} / \mathrm{ml}$. Concentrations of activin A and follistatin in follicular fluid were measured using the ELISAs described by Knight et al. (1996) and Tannetta et al. (1998) respectively. Within- and between- plate CVs were 9 and $10 \%$ for activin A and 5 and $7 \%$ for follistatin; detection limits were 200 and $300 \mathrm{pg} / \mathrm{ml}$ respectively. The activin A and follistatin assays were not suitable for measurement of peptide levels in ovine plasma.}

\section{Data analysis}

For data concerning ovarian histological analysis, follicles were grouped into two size classes as follows, class A: 1-4 mm; class B: $>4 \mathrm{~mm}$. Numbers of follicles were compared using Student's $t$-test or a Wilcoxon test; for all tests the significance level was $5 \%$. For data concerning biochemical characterization of follicles, follicles were allocated to three size classes, i.e. class $1(5-9 \mathrm{~mm})$, class 2 $(9-13 \mathrm{~mm})$ and class $3(13-17 \mathrm{~mm})$. In the control group, only class 1 follicles were present on ovaries. Within class 1 follicles, comparisons of means between control and AN group were performed by Student's $t$-test or a MannWhitney test. Within the AN group, comparison of means between follicular classes 1, 2 and 3 was performed by the non-parametric ANOVA of Kruskal-Wallis. It should be noted that the follicle size classes for histology differ from those used for the biochemical characterization of follicles since histological sizes were measured on paraffin sections and are reduced due to shrinkage, compared with sizes measured on fresh tissue.

For data concerning plasma FSH levels, the effects of $\mathrm{AN}$ and $\mathrm{PGF}_{2 \alpha}$ were analysed through comparison of Day 1 and Day 2 levels with those of Day 0 (day of AN), and Day 5 levels with those of Day 4 (day of $\mathrm{PGF}_{2 \alpha}$ ) respectively for the two groups using a one-factor ANOVA. Similarly, the effect of FO was analysed through comparison of levels at Day 1 or 7 with those at Day 0 (day of $\mathrm{FO}$ ) with a one-factor ANOVA.

For data concerning plasma LH levels, mean levels were analysed after $\log$ transformation and LH pulse frequency and amplitude were estimated by means of the Munro algorithm (Zaristow, Haddington, East Lothian, UK), a modified version of Merriam \& Wachter's (1982) program, G parameters being set at $P=0 \cdot 05$. For each of the three parameters of $\mathrm{LH}$ secretion, four periods were considered: before AN or SO (P1), after AN or SO surgery (P2), after $\mathrm{PGF}_{2 \alpha}(\mathrm{P} 3)$ and after $\mathrm{FO}(\mathrm{P} 4$; see 'serial sampling' in Fig. 1, experiment 2). The effect of AN, $\mathrm{PGF}_{2 \alpha}$ or ovariectomy was analysed for each parameter through comparison of $\mathrm{P} 2$ vs $\mathrm{P} 1, \mathrm{P} 3$ vs $\mathrm{P} 2$ and $\mathrm{P} 4$ vs $\mathrm{P} 3$ values respectively for both groups with a two-factor (period and group) ANOVA. When a significant $(P \leq 0 \cdot 05)$ level was reached for period $\times$ group interaction, this was followed by an ANOVA with factorial analysis within one group using the Scheffé post hoc test. For all analysis data were expressed as mean \pm s.E.M.

\section{Results}

\section{Preliminary experiment}

Ovarian histological analysis In the AN group, the left and right ovaries examined at the time of the ULO had ovulated and CL were present in all animals except one (Table 1). We did not observe any enlargement of either ovary at this time. At the time of FO, the right ovary had dramatically enlarged in all sheep and we observed a large diversity of luteal structures from early luteinization to complete luteinization of follicular cells in both nonruptured follicles and normal ovulated follicles (Table 1). The total number of class A follicles in the right (AN) ovary was significantly higher than in the left ovary: $21 \cdot 8 \pm 2 \cdot 2$ vs $15 \cdot 5 \pm 3 \cdot 0 \quad(P<0 \cdot 05)$. The proportion of atretic follicles in class A was similar in right $(0 \cdot 29)$ and left $(0 \cdot 35)$ ovaries $(P>0 \cdot 05)$. The total number of follicles in 
Table 1 Observations in the preliminary experiment on the number of $\mathrm{CL}$ and large LF on the ovaries of $\mathrm{AN}$ or SO ewes at the time of ULO (left ovary) and at subsequent removal of the AN or SO right ovary (FO)

\begin{tabular}{|c|c|c|c|c|c|c|}
\hline & \multirow[b]{2}{*}{ Breed $^{a}$} & \multicolumn{2}{|c|}{$\begin{array}{l}\text { No. of } C L \text { and size }(\mathrm{cm}) \\
\text { of right and left ovaries } \\
\text { at the time of ULO }\end{array}$} & \multicolumn{2}{|c|}{ Interval (days) } & \multirow{2}{*}{$\begin{array}{l}\text { No. of CL, LF and size } \\
(\mathrm{cm}) \text { of the right ovary at } \\
\text { the time of FO }\end{array}$} \\
\hline & & Left & Right & AN-ULO & ULO-FO & \\
\hline \multicolumn{7}{|l|}{ Group } \\
\hline \multirow[t]{7}{*}{ AN } & $\mathrm{R}$ & $1(2 \times 2)^{b}$ & $2(1 \times 1 \cdot 5)$ & 7 & 7 & 2 (LF) $(3 \times 3)$ \\
\hline & $\mathrm{R}$ & $2(2 \times 2)$ & $4(1.5 \times 1.5)$ & 5 & 14 & 7 (LF) $(4.5 \times 5)$ \\
\hline & IF & $1(2 \times 2)$ & $2(2 \times 2 \cdot 5)$ & 14 & 28 & $>10(\mathrm{LF})(6 \times 6)$ \\
\hline & $\mathrm{R}$ & $0(1 \times 1 \cdot 5)$ & $0(1.5 \times 2)$ & 5 & 7 & $5(\mathrm{LF})(3 \times 3)$ \\
\hline & IF & $1(3 \times 2 \cdot 5)$ & $1(1 \times 1)$ & 9 & 28 & $2(\mathrm{LF})(6 \times 5)$ \\
\hline & IF & $1(1 \cdot 5 \times 2)$ & $1(2 \times 2)$ & 7 & 5 & $4(\mathrm{LF}) 3(\mathrm{CL})(3.5 \times 3.5)$ \\
\hline & IF & - (?) & - (?) & 0 & 12 & $4(\mathrm{LF})(5 \times 5)$ \\
\hline \multirow[t]{4}{*}{ SO } & $\mathrm{R}$ & $0(1.5 \times 2)$ & $0(1.5 \times 2)$ & 0 & 5 & $0(\mathrm{CL})$ (many large follicles) (?) \\
\hline & IF & $1(?)$ & $0(?)$ & 0 & 9 & $1(\mathrm{CL})(2 \times 2)$ \\
\hline & IF & $2(1.5 \times 1.5)$ & $0(1 \times 1)$ & 0 & 5 & $2(\mathrm{CL})(1 \times 1)$ \\
\hline & IF & $1(?)$ & $0(?)$ & 0 & 9 & $1(\mathrm{CL})(?)$ \\
\hline
\end{tabular}

${ }^{\mathrm{a}} \mathrm{R}=$ Romanov; IF=Ile-de-France

${ }^{\mathrm{b}}$ From the two major axes.

class B was clearly larger in the right ovary than in the left $(4 \cdot 0 \pm 1 \cdot 0$ vs $0 \cdot 83 \pm 0 \cdot 4$ respectively; $P<0 \cdot 05)$. The proportion of atretic follicles $(0 \cdot 43)$ was the same in both ovaries.

In three out of four ewes in the SO group only the left ovary had ovulated at the time of ULO (presumably by chance; Table 1). At the time of FO the right ovary had normal ovulation numbers and was of normal size (Table 1). The average total number of class $A$ follicles was similar in the right ovary at the time of FO and the left ovary taken at the time of ULO $(17 \cdot 6 \pm 2 \cdot 5$ vs $19 \cdot 8 \pm 4 \cdot 0)$; the proportion of atretic follicles was the same in right $(0 \cdot 27)$ and left $(0 \cdot 32)$ ovaries. In the SO group most ovaries had no follicle in class B and statistical comparison between left and right ovary was not possible; the same remark applies to the estimation of the rate of atresia in this size class. Likewise, no comparison between breed was attempted due to the small numbers of animals of each breed.

\section{Experiment 2}

Ovarian histological analysis The results obtained in this experiment were consistent with those of the preliminary experiment. The in situ right ovary of AN ewes showed a dramatic enlargement due to the formation of multiple large follicles (see below) unlike those of the SO group, which remained of normal size. In the AN group, one ovary had five CL, two large luteinized follicles (LFs) and several other follicles larger than $18 \mathrm{~mm}$; another AN ovary had one CL and seven follicles larger than $12 \mathrm{~mm}$, and the three remaining AN ovaries each had several follicles larger than $12 \mathrm{~mm}$. In the SO group all ovaries displayed CL; four ovaries had two CL, and two ovaries had one CL; all had a few follicles, most of them being smaller than $8 \mathrm{~mm}$.
The two ovaries of AN ewes examined histologically had, respectively, 27 and 31 follicles in class A and five and eight follicles in class $\mathrm{B}$. The two ovaries of the $\mathrm{SO}$ group had, respectively, 26 and 19 follicles in class A and two and one in class B. The rate of atresia in class A and B follicles for ovaries of the AN and SO groups were, respectively, $0 \cdot 20$ and 0.15 (AN group) vs 0.31 and 0 (SO group).

\section{Characterization of follicles for steroidogenesis and} peptides of the inhibin system All the dissected follicles from control ovaries were 5-9 $\mathrm{mm}$ in diameter (class 1 follicles). In contrast, the size of dissected follicles from AN ovaries varied between 5 and $17 \mathrm{~mm}$ in diameter and follicles were allocated to size classes 1,2 and 3. By microscopical examination of smears of granulosa cells, 18 out of 19 and 5 out of 6 follicles recovered from AN and control ovaries respectively were judged healthy; atretic follicles were excluded from subsequent analysis. When class 1 follicles were considered, intrafollicular concentrations of oestradiol-17 $\beta$ and progesterone were higher (both $P<0 \cdot 01$ ) and intrafollicular concentrations of follistatin were lower $(P<0 \cdot 001)$ in the AN group, compared with the control group (Table 2). In addition, class 1 follicles from these groups tended to differ for intrafollicular androstenedione concentrations $(P=0 \cdot 055)$ but did not differ for aromatase activity of granulosa cells or for intrafollicular concentrations of inhibin A and activin A. When the AN group was considered, oestradiol-17 $\beta$ and androstenedione concentrations in follicular fluid decreased to very low values between class 1 and class 3 (both $P<0 \cdot 01)$, whereas progesterone concentrations strongly increased $(P<0 \cdot 01)$ and aromatase activity remained unchanged (Table 2). In addition, in the AN group, intrafollicular concentrations of inhibin A 
Table 2 Aromatase activity of granulosa cells and concentrations of steroids and inhibin-related peptides in follicular fluids (mean \pm S.E.M.) from follicles of control and AN ovaries. Follicles were classified according to diameter: class 1: 5-9 mm; class 2: 9-13 mm; class 3: $13-17 \mathrm{~mm}$ )

\begin{tabular}{|c|c|c|c|c|}
\hline & Class 1 control $(n=5)$ & Class 1 AN $(n=5)$ & Class 2 AN $(n=6)$ & Class 3 AN $(n=6)$ \\
\hline Aromatase activity (pg oestradiol- $17 \beta / 10^{5}$ cells/h) & $566 \pm 179$ & $1050 \pm 353$ & $2593 \pm 1470$ & $545 \pm 167$ \\
\hline Oestradiol-17 $\beta(\mathrm{ng} / \mathrm{ml})$ & $174 \pm 60^{*}$ & $621 \pm 95$ & $329 \pm 112$ & $0 \cdot 5 \pm 0 \cdot 1^{\S}$ \\
\hline Progesterone $(\mathrm{ng} / \mathrm{ml})$ & $24 \pm 1^{*}$ & $68 \pm 11$ & $912 \pm 406$ & $2411 \pm 372^{\S}$ \\
\hline Inhibin $A(\mu \mathrm{g} / \mathrm{ml})$ & $12 \cdot 62 \pm 0 \cdot 89$ & $10 \cdot 68 \pm 0 \cdot 81$ & $3 \cdot 83 \pm 1 \cdot 45$ & $0 \cdot 31 \pm 0 \cdot 02^{\S}$ \\
\hline Activin A ( $\mu \mathrm{g} / \mathrm{ml})$ & $2 \cdot 61 \pm 0 \cdot 25$ & $1 \cdot 80 \pm 0 \cdot 35$ & $0 \cdot 84 \pm 0 \cdot 24$ & $0 \cdot 89 \pm 0 \cdot 38^{\S}$ \\
\hline Follistatin $(\mu \mathrm{g} / \mathrm{ml})$ & $3 \cdot 82 \pm 0 \cdot 22^{*}$ & $1 \cdot 26 \pm 0 \cdot 26$ & $0 \cdot 47 \pm 0 \cdot 27$ & $0 \cdot 13 \pm 0 \cdot 004^{\S}$ \\
\hline
\end{tabular}

${ }^{*} P<0 \cdot 01$ class 1 control vs class $1 \mathrm{AN}$.

$* * P=0 \cdot 055$, class 1 control vs class 1 AN.

${ }^{\S} P<0 \cdot 05$, class 2 or class 3 AN vs class $1 \mathrm{AN}$.

$(P<0 \cdot 01)$, follistatin $(P<0 \cdot 01)$ and, to a lesser extent activin $A(P<0 \cdot 05)$, decreased between class 1 and class 3 (Table 2).

\section{Plasma steroids and inhibin in ovarian vein and hepatic vein blood and in the peripheral circulation}

The levels of oestradiol-17 $\beta$ and progesterone were very high in the ovarian venous blood of both $\mathrm{AN}$ and $\mathrm{SO}$ groups (Table 3 ). In the AN group we observed a dramatic drop in steroid levels in the hepatic vein compared with those in the ovarian vein. Nevertheless steroid levels in blood draining the liver were significantly higher in the AN group than in the SO group (Table 3). The peripheral oestradiol and progesterone levels were also markedly decreased in the AN group (Table 3). Inhibin levels in the ovarian and hepatic venous blood in the AN group were not significantly different. However, in the $\mathrm{SO}$ group inhibin levels were significantly higher $(P<0 \cdot 05)$ in the ovarian vein than in hepatic venous blood.

Plasma gonadotrophin levels Two ewes from the AN group were excluded from the analysis as they showed a preovulatory LH response after $\mathrm{PGF}_{2 \alpha}$ injection. This strongly suggests that the amount of oestradiol-17 $\beta$ that was reaching the hypothalamo-pituitary system was sufficient to activate preovulatory releases of LH-releasing hormone and $\mathrm{LH}$, therefore raising some doubt about the efficiency of the AN surgery in these two ewes.

Response to AN procedure Figures 2 and 3 show that mean LH levels were clearly increased after AN while levels were not changed in SO ewes $(P=0.001$ for period $\times$ treatment interaction, two-factor ANOVA; $P<0 \cdot 01$ for period effect in AN group). This was partly due to a $2 \cdot 6$-fold increase in LH pulse frequency $(P=0.015$ for period $\times$ treatment interaction, two-factor ANOVA; $P<0.007$ for period effect in AN group). $\mathrm{LH}$ pulse amplitude tended to increase $\sim 3$-fold after AN but not after $\mathrm{SO}(P=0.04$ for period $\times$ treatment interaction, two-factor ANOVA; $P<0.08$ for period effect within AN group).
Comparison of plasma FSH levels on day 1 and 2 after AN/SO surgery, with those at day 0 , for AN versus SO groups, revealed a treatment $\times$ day interaction $(P \leq 0 \cdot 05$, two-factor ANOVA). Thus, AN induced a significant $(+60 \% ; P<0 \cdot 05)$ increase in plasma FSH while no effect was observed in the SO group. Unexpectedly, plasma FSH levels were higher at Day 0 in the SO than in the AN group (Fig. 4). However, it is interesting to note that individual two-day values before (Day 1, Day 0) and after $\mathrm{AN}(\mathrm{Day}+1$, Day +2) were unchanged or decreased in SO ewes while they were all increased in AN ewes (Fig. 5).

Response to $\mathbf{P G F}_{\mathbf{2 \alpha}}$ injection As shown in Figs 2 and 3, mean plasma LH levels, LH pulse frequency and pulse amplitude were not changed after $\mathrm{PGF}_{2 \alpha}$ injection in either $\mathrm{AN}$ or $\mathrm{SO}$ groups $(P>0 \cdot 17$ for period $\times$ treatment interaction, two-factor ANOVA for each parameter).

Comparison of plasma FSH levels $24 \mathrm{~h}$ after $\mathrm{PGF}_{2 \alpha}$ injection with those on the day of injection (i.e. Day 4 of Fig. 1) did not reveal any effect in either AN or SO groups $(P>0.8$ for treatment $\times$ day interaction; Fig. 4A).

Response to removal of remaining ovary As shown in Figs 2 and 3, mean plasma LH levels and LH pulse amplitude in the $\mathrm{SO}$ group increased markedly after FO $(P<0 \cdot 01)$. In $\mathrm{AN}$ ewes the increases were much less pronounced and not statistically significant. LH pulse frequency tended to be increased after $\mathrm{FO}$ in the SO group $(P=0.07)$ but not in the AN group. Ovariectomy induced a marked and rapid (within 1 day) increase in plasma FSH levels in both AN $(P<0 \cdot 0001)$ and SO $(P<0 \cdot 0001)$ groups (Fig. 4B).

\section{Discussion}

In ULO ewes, AN of the ovarian vein to the mesenteric vein induced marked changes in follicular development, and in the secretion of gonadotrophins and ovarian steroids. Several follicles enlarged up to $12-17 \mathrm{~mm}$ in 


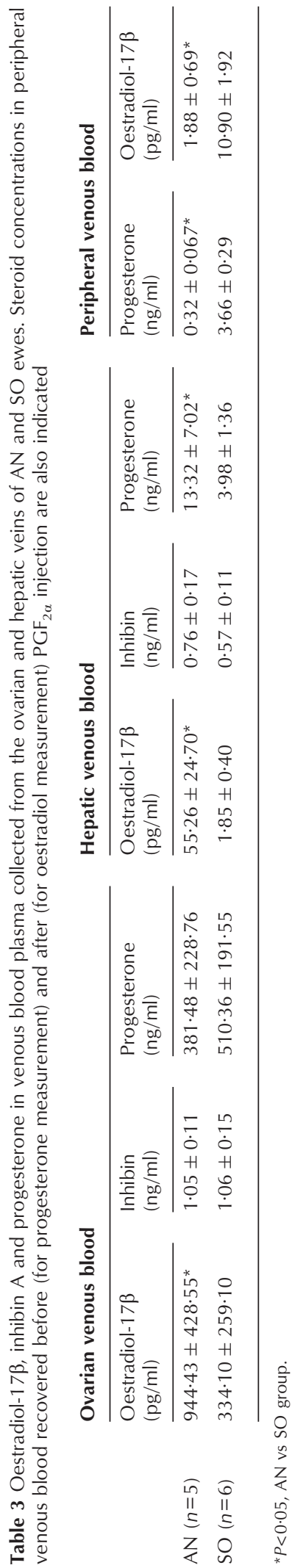



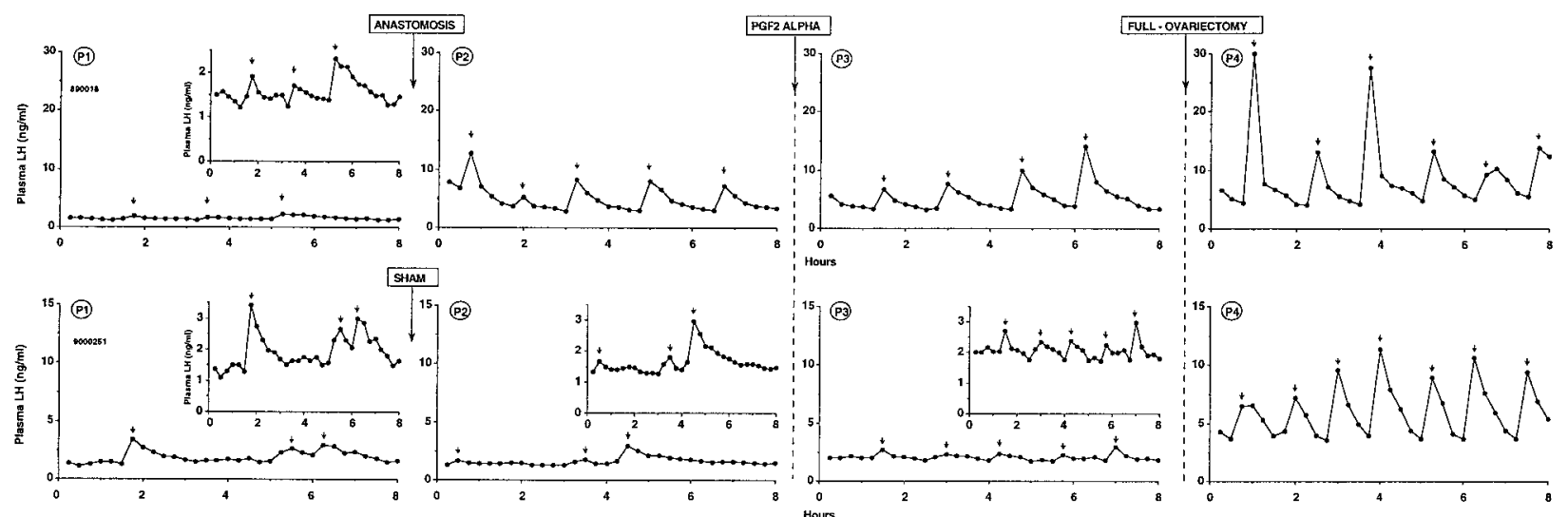

Figure 2 Individual representative patterns of plasma LH in anastomosed (upper panels) and sham operated (bottom panels) ewes in experiment 2. P1, P2, P3, P4 are $8 \mathrm{~h}$ sampling periods separated by AN of the right ovarian vein to the hepatic portal vein, $\mathrm{PGF}_{2 \alpha}$ injection and FO respectively. Ewes were blood sampled every 15 min. Note that all ewes underwent ULO at the start of the experiment. For further details, see Materials and Methods and Fig. 1. Note that the $y$ axis scale is different for upper and bottom panels. The inserts show the plasma LH profiles with an expanded $y$ axis to show LH pulses more clearly (arrows).

diameter and their follicular fluid contained high steroid levels after the AN procedure. However, steroid concentrations in peripheral plasma were markedly reduced after AN. The frequency and amplitude of LH pulses also increased markedly but there was only a slight increase in plasma FSH level. When AN was performed with the contralateral ovary still present, hypertrophy and increased follicular development of the AN ovary was delayed until the contralateral ovary was removed. Thus, adjustments in steroid feedback by the contralateral ovary are thought to compensate for the removal by the liver of steroids secreted by the AN ovary and thus prevent the increase in trophic drive from the hypothalamo-pituitary system.

Our experimental model in the ewe exhibits similarities with a previously described model in which the ovary was autografted within the spleen of the rat (Biskind \& Biskind 1944), guinea pig (Lipschütz et al. 1946) or rabbit (Koulicher 1960). In these models, as in ours, almost all ovarian steroids are catabolized by the liver, and only when the contralateral ovary is removed does the grafted ovary become hypertrophied (Von Fels et al. 1970). Nevertheless many of the authors who grafted the ovary inside the spleen observed that tumours developed in the ovary (Biskind \& Biskind 1944, Von Fels et al. 1970). We never observed such tumours after AN of the sheep ovary. Moreover, difficulties inherent to the ovarian autograft procedure may complicate the interpretation of results; particularly the extent to which the vascularization of large follicles is re-established. Certainly, encystement of the ovary inside the spleen tissues may complicate histological evaluation (Leavitt 1968, Von Fels et al. 1970). The present model involving surgical AN of the ovarian vein avoids such drawbacks. Moreover, the neural and vascular connections of the ovary remain largely intact and after
AN the follicles exhibited normal morphology and could ovulate normally, at least when the contralateral ovary was present.

As mentioned above, the most striking consequence of AN on the ovary, observed only when the contralateral ovary was absent, was its dramatic enlargement due to an increased number of very large follicles, some of which had luteinized by the time of ovariectomy 9-14 days later. Both luteinized and non-luteinized follicles on AN ovaries were larger than normal preovulatory follicles in control ewes. Histology showed that, in comparison with SO ovaries, AN ovaries had a similar number of follicles of 1-4 $\mathrm{mm}$. Furthermore, we showed that the large follicles (up to $13 \mathrm{~mm}$ diameter) of the AN group contained higher concentrations of oestradiol, progesterone, and androstenedione than preovulatory follicles of the control group. However, in the largest follicles $(13-17 \mathrm{~mm})$ oestradiol and androstenedione concentrations were much reduced while progesterone concentrations increased dramatically, probably reflecting the fact that these follicles had indeed luteinized. Interestingly, progesterone levels secreted by LFs in the AN group and by CL in the SO group were similar (Table 3). In parallel, intrafollicular concentrations of inhibin A, activin A and follistatin decreased progressively in the AN group as follicles enlarged up to $17 \mathrm{~mm}$ in diameter. This is consistent with reports that expression of inhibin $\alpha$ and $\beta$ A subunit mRNAs decrease during luteinization in the sow (Guthrie et al. 1992) and cow (Juengel et al. 1993, Hopko Ireland \& Ireland 1994) and that expression of follistatin mRNA as well as intrafollicular concentrations of follistatin decreases after the preovulatory LH surge in the sow (Li et al. 1997).

Information on changes in FSH and LH secretion in rats induced by grafting of the ovary within the spleen is 

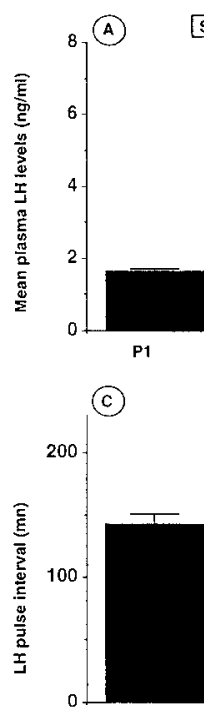

P1

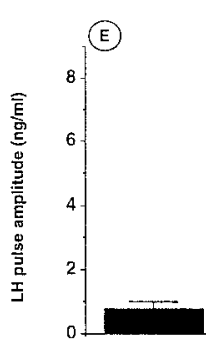

P1
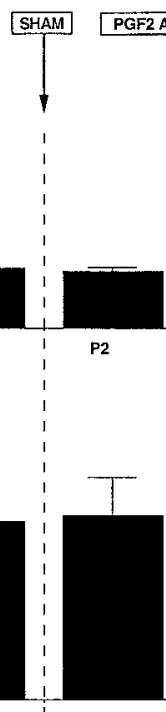

$\mathbf{P}$

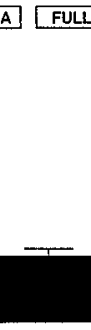

P3

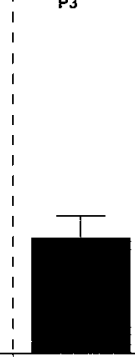

P3

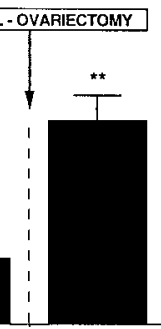

P4

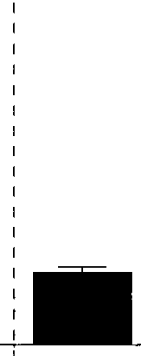

$\mathrm{P} 4$

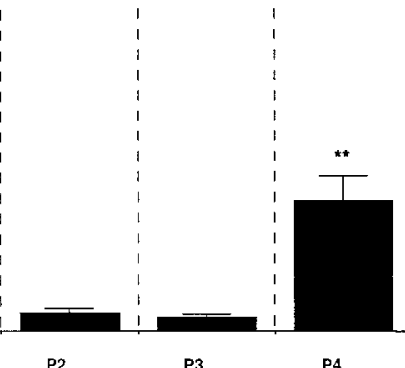

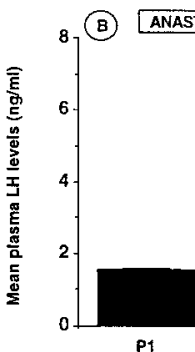

(D)

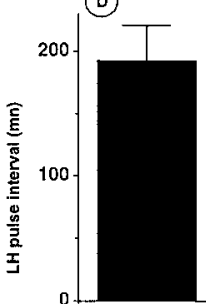

(F)

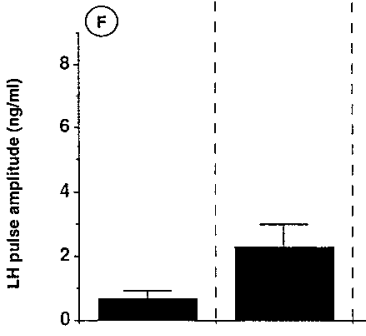

P1

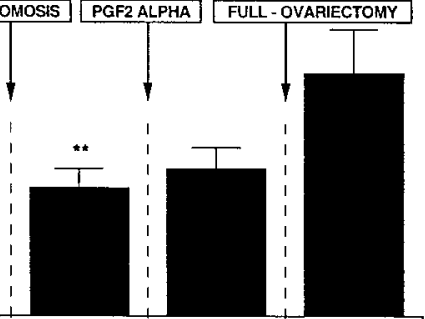

P2

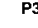

P4

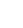

Figure 3 Effect of $\mathrm{SO}(\mathrm{A}, \mathrm{C}, \mathrm{E})$ or $\mathrm{AN}(\mathrm{B}, \mathrm{D}, \mathrm{E})$ followed by $\mathrm{PGF}_{2 \alpha}$ injection and $\mathrm{FO}$ on mean $\mathrm{LH}$ plasma levels (A, B), LH pulse interval (C, D) and amplitude (E, F) in ewes (experiment 2). During each period (P1, $\mathrm{P} 2, \mathrm{P} 3, \mathrm{P} 4)$ ewes were blood sampled every $15 \mathrm{~min}$ for $8 \mathrm{~h}$. Comparisons were made for each parameter between P1 and P2, P2 and P3, P3 and P4 with a two-factor ANOVA eventually followed by a withintreatment one-factor (period) ANOVA. ${ }^{* *} P \leq 0 \cdot 01$ Note that all ewes underwent ULO before starting the experiment.

sparse (Greep \& Jones 1950, Leavitt 1968). However, Uilenbroek et al. (1978) and Charlesworth (1985) noted raised plasma LH levels after transplanting one ovary into the spleen of a castrated rat and a sharp decrease in FSH levels. The suppression in FSH secretion presumably reflects the action of inhibin secreted by the grafted
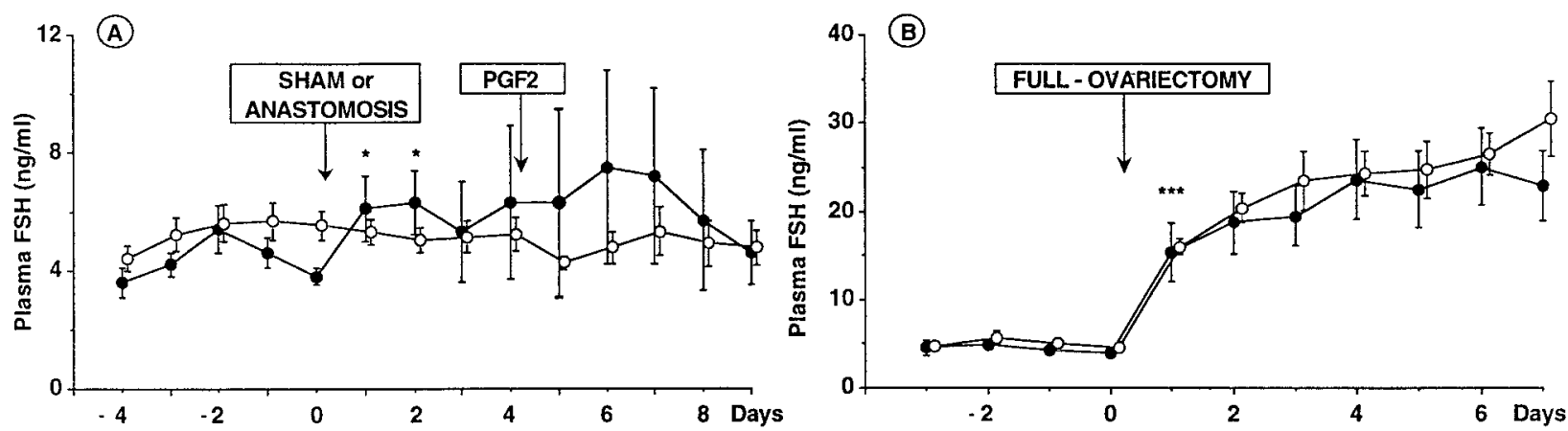

Figure 4 Effects of $A N$ and $\mathrm{PGF}_{2 \alpha}$ injection $(\mathrm{A})$ and subsequent $\mathrm{FO}(\mathrm{B})$ on plasma FSH levels in ewes in experiment 2. (A) Arrows indicate the time of AN (Day 0) and PFG2 $\alpha$ (Day 4). Comparison with Day 0 levels: ${ }^{*} P<0 \cdot 05$. (B) FO is indicated by the arrow (Day 0 ). Comparison with Day 0 levels: ${ }^{* *} P<0 \cdot 001$. Note that the scale of the $y$ axis is different in (A) and (B). AN ewes; $\bigcirc$ SO ewes. 

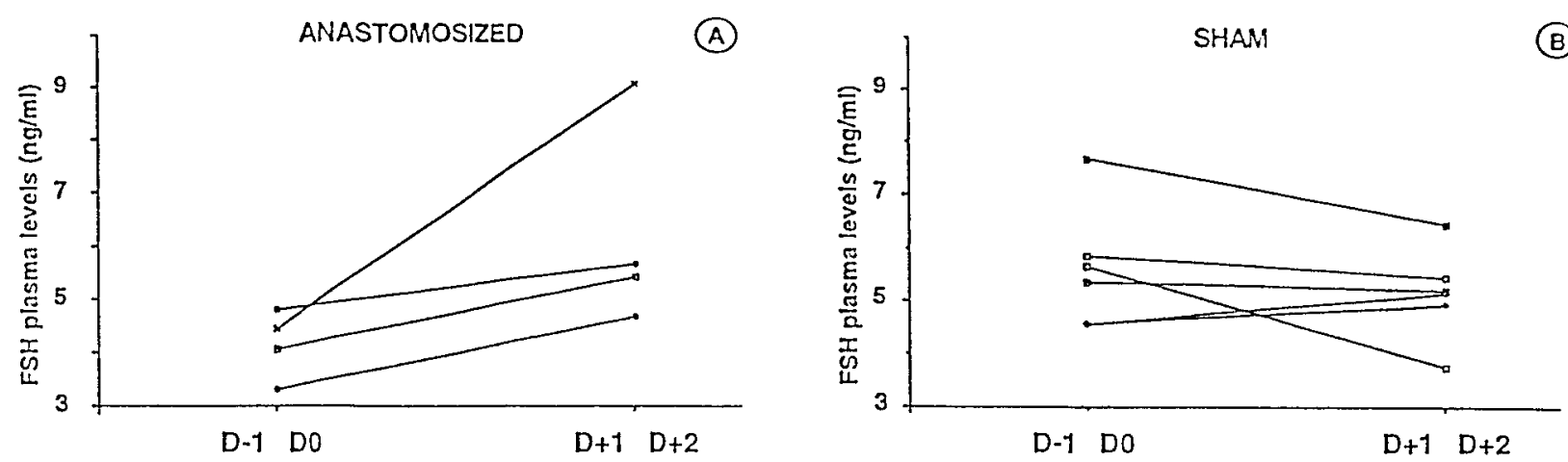

Figure 5 Individual variations of plasma FSH levels in response to AN (A) or SO (B) of ewes in experiment 2. Each symbol represents mean FSH levels at Days -1 and $0(D-1$ D0) and Days +1 and $+2(D+1 D+2)$ for each ewe.

ovary. In our ULO ewes, the AN-induced increase in LH secretion was not accompanied by a sustained elevation in FSH as observed subsequently after FO. Inhibin A was poorly inactivated by the liver and this observation could explain why in most animals having large follicles secreting inhibin at the time of AN, the FSH levels did not increase very much after AN. In contrast to FSH the mean level and pattern of LH secretion were dramatically altered after AN; both frequency and amplitude of LH pulses increased as seen during the late follicular phase of a normal cycle (Baird \& McNeilly 1981). Even though the steroids were not completely catabolized by the liver, the levels of oestradiol and progesterone that leave the liver and reach the general circulation in the AN animals were considerably less in the SO group shortly before (oestradiol) and after (progesterone) ovulation.

In our experimental model, we evidently disrupted the last mechanism of selection of large follicles and prevented ovulation by modifying the secretion of gonadotrophins. We propose that as a consequence of decreased peripheral steroid levels after AN, a substantial increase in $\mathrm{LH}$ pulsatility occurs that is maintained for many days with only a slight and transient increase in FSH secretion. This promotes the continuous recruitment and enlargement of follicles, most of which become luteinized under high LH levels, but which fail to ovulate in the absence of a preovulatory LH surge. Clearly, the normal LH surge mechanism involving a positive feedback action of follicular oestradiol on the hypothalamo-pituitary system cannot operate in these AN ewes. It has been shown that an increase in LH pulsatility either by continuous hourly injections of exogenous ovine LH in the sheep (Dobson et al. 1997) or by administration of low doses of progestagens in the sheep (Johnson et al. 1996) or in the cow (Sanchez et al. 1995) induced persistent follicles secreting androstenedione, oestradiol and inhibin. In sheep such large follicles secrete higher levels of oestradiol than the controls but then become atretic after approximately 10 days of sustained growth (Dobson et al. 1997).
Campbell et al. (1995) showed also that in ewes treated with an antagonist of gonadotrophin-releasing hormone, a 3-day infusion of FSH recruits new follicles. Some of these follicles become responsive to stimulation by large pulses of LH and are capable of secreting high levels of oestradiol. A surge of oestradiol could be released by such follicles in response to one human chorionic gonadotrophin injection.

In conclusion, in ULO ewes, surgical AN of the remaining ovary to the hepatic portal vein promotes a marked and sustained increase in LH pulsatility with only a marginal and transient increase in FSH secretion. This is associated with a dramatic enlargement of large antral follicles present on the in situ ovary at the time of AN. Such a phenomenon does not take place when the normal contralateral ovary is present, in which case both ovaries ovulate a similar number of follicles. Thus, withdrawal of the normal ovary prevents compensatory feedback control on the hypothalamo-pituitary system and induces a marked increase in pulsatile $\mathrm{LH}$ secretion which is largely responsible for the modifications to the AN ovary we describe here. In normal sheep, however, the negative feedback actions of both steroids and inhibin on FSH secretion are essential for the control of follicle selection and for setting ovulation rate (Henderson et al. 1988, Mann et al. 1992). Since in the present ULO ewes only a small and transient increase in plasma FSH level was observed after the AN procedure, our observations lead us to propose that a marked increase in $\mathrm{LH}$ pulsatility may considerably enhance the effects of a relatively steady level of FSH on the growth and number of large follicles in sheep.

\section{Acknowledgements}

We wish to thank G Durand, F Paulmier and their staff for the care of animals, $M$ Charker-Jaros for typing the manuscript, Dr Y Combarnous, Nouzilly, France for LH 
CY 1051, Dr H G Grimek, Wisconsin, USA for FSH HG 225 and Prof. N P Groome, Oxford, UK for antibodies used in the assays for inhibin, activin and follistatin.

\section{References}

Baird DT \& McNeilly AS 1981 Gonadotrophic control of follicular development and function during the oestrous cycle of the ewe. Journal of Reproduction and Fertility 30 119-133.

Biskind MS \& Biskind GR 1944 Development of tumors in the rat ovary after transplantation into the spleen. Proceedings of the Society for Experimental Biology and Medicine 55 176-179.

Blanc MR \& Poirier JC 1979 A new homologous radioimmunoassay for ovine follicle stimulating hormone development and characterization Annales de Biologie Animale, Biochimie et Biophysique 19 1011-1026.

Bosc MJ \& Nicolle A 1997 Steroid productions by co-cultures of granulosa cells with inner and outer thecal cells in preovulatory follicles of gonadotrophin stimulated calves. Journal of Steroid Biochemistry and Molecular Biology 62 213-221.

Brown JB 1978 Pituitary control of ovarian function - concepts derived from gonadotrophin therapy. Australian and New Zealand Journal of Obstetrics and Gynaecology 18 47-54.

Campbell BK \& Scaramuzzi RJ 1995 The effect of acute immunoneutralisation of inhibin in ewes during the late luteal phase of the oestrous cycle on ovarian hormone secretion and follicular development during the subsequent follicular phase. Journal of Reproduction and Fertility 104 337-345.

Campbell BK, Scaramuzzi RJ, Evans G \& Downing JA 1991 Increased ovulation rate in androstenedione-immune ewes is not due to elevated plasma concentration of FSH. Journal of Reproduction and Fertility 91 655-666.

Campbell BK, Scaramuzzi RJ \& Webb R 1995 Control of antral follicle development and selection in sheep and cattle. Journal of Reproduction and Fertility 49 335-350.

Charlesworth MC 1985 Differential LH and FSH release due to ovarian transplants in the spleen. Proceedings of the 5th Ovarian Workshop, pp 45-49. Eds DO Toft \& RJ Ryan.

Dobson H, Campbell BK, Gordon BM \& Scaramuzzi RJ 1997 Endocrine activity of induced persistent follicles in sheep. Biology of Reproduction 56 208-213.

Garcès D \& Mariana JC 1997 Anastomosis between ovarian and mesenteric veins in sheep: induction of a physiological hyperstimulation of the ovary. Journal of Surgical Research 72 15-21.

Greep RO \& Jones IC 1950 Steroid control of pituitary function. Recent Progress in Hormone Research 5 197-261.

Guthrie HD, Rohan RM, Rexroad CE \& Cooper BS 1992 Changes in concentrations of follicular inhibin alpha and beta A subunit messenger ribonucleic acids and inhibin immunoactivity during preovulatory maturation in the pig. Biology of Reproduction $\mathbf{4 7}$ 1018-1025.

Henderson KM, Savage LC, Ellen RL, Ball K \& McNatty KP 1988 Consequences of increasing or decreasing plasma FSH concentrations during the preovulatory period in Romney ewes. Journal of Reproduction and Fertility 84 187-196.

Hopko Ireland JL \& Ireland JJ 1994 Changes in expression of inhibin/activin $\alpha \beta_{\mathrm{A}}$ and $\beta_{\mathrm{B}}$ subunit messenger ribonucleic acids following increase in size and during different stages of differentiation or atresia of non ovulatory follicles in cows. Biology of Reproduction 50 492-501.

Johnson SK, Dailey RA, Inskeep EK \& Lewis PE 1996 Effect of peripheral concentrations of progesterone on follicular growth and fertility in ewes. Domestic Animal Endocrinology 13 69-79.

Juengel JL, Imakawa K, Farin PW, Youngquist RS, Smith MF \& Garverick HA 1993 Detection of mRNA for inhibin alpha and beta $A$ subunits in bovine ovarian tissues and the effect of in vivo administration of GnRH. Domestic Animal Endocrinology 10 207-218.

Knight PG 1996 Roles of inhibins, activins and follistatin in the female reproductive system. Frontiers in Neuroendocrinology $\mathbf{1 7}$ 476-509.

Knight PG, Muttukrishna S \& Groome NP 1996 Development and application of a two-site enzyme immunoassay for the determination of 'total' activin-A concentrations in serum and follicular fluid. Journal of Endocrinology 148 267-279.

Knight PG, Feist SA, Tannetta DS, Bleach ECL, Fowler PA, O'Brien M \& Groome NP 1998 Measurement of inhibin A ( $\alpha-\beta$ A dimer) during the oestrous cycle, after manipulation of ovarian activity and during pregnancy in the ewe. Journal of Reproduction and Fertility 113 159-166.

Koulischer L 1960 Greffes intraspléniques d'ovaire chez la lapine castrée. Annales d'Endocrinologie 21 314-320.

Leavitt WW 1968 Transplantation of the upper reproductive tract to the spleen in the female rat: a method for studying the pituitarygonadal relationship. Ohio Journal of Science 68 50-68.

Li MD, De Paolo LV \& Ford JJ 1997 Expression of follistatin and inhibin/activin subunit genes in porcine follicles. Biology of Reproduction 57 112-118.

Lipschütz A, Ponce de Leon H, Woywood E \& Gay O 1946 Intrasplenic ovarian grafts in the guinea pig and the problem of neoplastic reactions of the graft. Revue Canadienne de Biologie $\mathbf{5}$ 181-198.

Mann GE, Campbell BK, McNeilly AS \& Baird DT 1989 Passively immunizing ewes against inhibin during the luteal phase of the oestrous cycle raises the plasma concentrations of FSH. Journal of Endocrinology 123 383-391.

Mann GE, Campbell BK, McNeilly AS \& Baird DT 1992 The role of inhibin and oestradiol in the control of FSH secretion in the sheep. Journal of Endocrinology 133 381-391.

Mariana JC 1970 Etude sur le nombre d'ovulations obtenues après injection de PMSG chez la vache: notion de seuil de réponse. Annales de Biologie Animale, Biochimie et Biophysique 10 575-579.

Martensz ND \& Scaramuzzi RJ 1979 Plasma concentrations of luteinizing hormone, follicle-stimulating hormone and progesterone during the breeding season in ewes immunized against androstenedione or testosterone. Journal of Endocrinology 81 249-259.

Martensz ND, Scaramuzzi RJ \& Van Look PFA 1979 Plasma concentrations of luteinizing hormone and follicle-stimulating hormone during anoestrus in ewes actively immunized against oestradiol-17ß or testosterone. Journal of Endocrinology 81 261-269.

McNeilly AS, Crow W, Brooks J \& Evans G 1992 Luteinizing hormone pulses, follicle-stimulating hormone and control of follicle selection in sheep. Journal of Reproduction and Fertility 45 5-19.

Ménézo Y 1976 Milieu synthétique pour la survie et la maturation des gamètes et pour la culture de l'œuf fécondé. Compte Rendus de l'Académie des Sciences, Paris 282 1967-1970.

Merriam GR \& Wachter KW 1982 Algorithms for the study of episodic hormone secretion. American Journal of Physiology 243 E310-E318.

Monniaux D 1987 Short-term effects of FSH in vitro on granulosa cells of individual sheep follicles. Journal of Reproduction and Fertility $\mathbf{7 9}$ 505-515.

Pelletier J, Kann G, Dolais J, Rosselin G 1968 Dosage radioimmunologique de l'hormone lutéinisante plasmatique chez le mouton. Mise au point de la technique de dosage. Compte Rendus de l'Académie des Sciences, Paris, Serie D 266 2291-2294.

Picton HM \& McNeilly AS 1991 Evidence to support a folliclestimulating hormone, threshold theory for follicle selection in ewes chronically treated with gonadotrophin-releasing hormone agonist. Journal of Reproduction and Fertility 93 43-51.

Sanchez T, Wehrman ME, Kojima FN, Cupp AS, Bergfeld EG, Peters KE, Mariscal V, Kittok RJ \& Kinder JE 1995 Dosage of the 
synthetic progestin, norgestomet, influences luteinizing hormone pulse frequency and endogenous secretion of $17 \beta$-estradiol in heifers. Biology of Reproduction 52 464-469.

Saumande J 1981 Radioimmunoassay of estradiol-17 $\beta$ in unextracted ewe plasma. Steroids 38 425-437.

Saumande J, Tamboura D \& Chupin D 1985 Changes in milk and plasma concentration of progesterone in cows after treatment to induce superovulation and their relationships with number of ovulations and of embryos collected. Theriogenology 23 719-731.

Scaramuzzi RJ, Adams NR, Baird DT, Campbell BK, Downing JA, Findlay JK, Henderson KM, Martin GB, McNatty KP, McNeilly AS \& Tsonis CG 1993 A model for follicle selection and the determination of ovulation rate in the ewe. Reproduction, Fertility and Development 5 459-478.

Tannetta DS, Feist SA, Bleach ECL, Groome NP, Evans LW \& Knight PG 1998 Effects of active immunization of sheep against an amino terminal peptide of the inhibin $\alpha \mathrm{C}$ subunit on intrafollicular levels of activin A, inhibin A and follistatin. Journal of Endocrinology 157 157-168.

Terqui M, Wrathall JHM, Driancourt MA \& Knight PG 1995

Modulation of ovarian function by steroid and inhibin immunization. Livestock Production Science 42 181-192.
Thibier M \& Saumande J 1975 Oestradiol-17ß, progesterone and $17 \alpha$-hydroxyprogesterone concentrations in jugular venous plasma in cows prior to and during oestrous. Journal of Steroid Biochemistry 6 1433-1437.

Uilenbroek J Th J, Tiller R, de Jong FH \& Vels F 1978 Specific suppression of follicle-stimulating hormone secretion in gonadectomized male and female rats with intrasplenic ovarian transplants. Journal of Endocrinology 78 399-406.

Von Fels E, Bosch LR \& Zurro AR 1970 Die lebensfähigkeit des in die Milz implantierten ovarium. Endokrinologie 56 213-217.

Wheaton JE, Thomas DL, Kusina NT, Gottfredson RG \& Meyer RL 1996 Effects of passive immunization against inhibin-peptide on secretion of follicle-stimulating hormone and ovulation rate in ewes carrying the Booroola fecundity gene. Biology of Reproduction $\mathbf{5 5}$ $1351-1355$.

Received 23 December 1998

Revised manuscript received 9 August 1999

Accepted 8 December 1999 